\title{
A NEW APPROACH TO THE EUROPEAN PROGRAMME FOR CRITICAL INFRASTRUCTURE PROTECTION Gheorghe UDEANU
}

\author{
"Nicolae Bălcescu" Land Forces Academy, Sibiu, \\ udeanu@armyacademy.ro
}

\begin{abstract}
Critical infrastructure protection is the only way of ensuring the continuity of critical services in the society. A European critical infrastructure means "an asset, a system or part of it, located on the territory of the Member States, which is essential for the maintenance of vital societal functions, health, safety, security, economic or social well-being of people, and the disruption or destruction of which would have a significant impact in a Member State as a result of the failure to maintain those functions [1]."

To ensure a high level of protection of the European critical infrastructures and by increasing their resilience (against all of the threats and hazards) the consequences of the loss of services of the society as a whole can be reduced. At the same time, these are the objectives of the Stockholm Program [2] and of the National Security Strategy of the European Union [3].
\end{abstract}

Keywords: critical infrastructure protection, transnational risks a new approach, resiliency, interdependencies, review

\section{General Context}

The profound changes that occurred in the world over the last century expanded the geopolitical confrontations. At the same time with older trials for the establishment or maintenance of the spheres of interest, we are contemporaries of new rivalries, especially at the economic and religious level, both between states as well as within them. Thus, the assertion is confirmed, namely that in order to continue to exist, people are in need of vital space, of course, not in the sense of territorial expansion, otherwise they are condemned to dismantling and subsequently to extinction. Therefore, the world geopolitics must be thought globally, to enable a uniform solution, using the same unit of measure, for any problem, in any area of the planet. Today's challenges, more complex in nature, belong, in general, to terrorism, the organized crime, threats to the environment, and critical infrastructure.
New risks of a transnational type need an integrative approach that ensures both the use of new tools and techniques, as well as a strategy to respond to the asymmetric threats.

Typological diversified area of hazards and threats to critical infrastructure has resulted in the need for a revision of the European Program for Critical Infrastructure Protection, promotion of a revised form of the program, as well as practical arrangements for its implementation.

\section{Objectives}

The new approach to the European Program for Critical Infrastructure Protection is based on the revision of the program [4] in 2006 and on the Council of Europe's Directive No. 114/2008 [5], which reflects the choices of the Member States of the European Union, as well as of interested parties in this complex field. 
The revised version contains an inventory of the elements of the existing program and proposes a new approach to problems in the field based on the implementation of activities on prevention, preparedness and response.

An important component of the revised program addresses the interdependence [6] of the critical infrastructures in different sectors. The threats to a single infrastructure can have a significant impact on a large number of facilities from other sectors of activity and, what is even more serious spreads in the cascade effect affecting the infrastructures of other states as a result of the cross-border dimensions of many critical infrastructures. Of course, one aspect that cannot be neglected is represented by the interrelationship between what is critical infrastructure belonging to a single sector but with effects on other European countries. Such an example is the European network of high-voltage electricity, made up of national networks of high voltage electricity.

The process for the revision of the present European Program for Critical Infrastructure Protection [7] highlighted the fact that, so far, there has not been a great emphasis on the connections between critical infrastructures located in various sectors and neither on those beyond national borders. In order to protect critical infrastructures in an appropriate manner and to ensure a high level of resiliency a new approach that will cover this gap is required. To correctly identify the needs to improve the program it was decided to focus and target the efforts on four critical infrastructures of European dimension: EUROCONTROL [8], Galileo [9], the electricity transmission network [10] and the gas transmission network [11].

These were selected due to their panEuropean nature. On the basis of the conclusions they expect that other relevant infrastructures to be able to benefit from the results of this process and the tools developed in the activities with the 4
European critical infrastructures mentioned above.

\section{The review of the present program}

In its communication on a European Program for Critical Infrastructure Protection of December 12, 2006, the Commission established an overall policy approach and a framework for the protection of critical infrastructures in the European Union. The new proposed approach will focus on the existing framework, in particular on its strength and the discrepancies identified during the review process.

The four main directions of the present European Program for Critical Infrastructure Protection are:

- a procedure for the identification and designation of European critical infrastructures and the assessment of the need to improve their protection (presented in detail in Directive No. $114 / 2008$ of the Council of Europe);

- measures to facilitate the implementation of the European Program for Critical Infrastructure Protection, including an Action Plan, CIWIN, the use of groups of experts on the protection of critical infrastructures at EU level, a process of exchange of information in the reference field and identification and analysis of interdependencies;

- financing of measurements for the protection of critical infrastructure and projects on "Prevention, Preparedness and Consequences of the Management of Terrorism and other security related risks" for the period 2007-2013;

- the development of an external dimension of the European Program of for Critical Infrastructure Protection.

\subsection{Directive No. 114/2008 of the Council of Europe related to the European critical infrastructures}

Although the Directive No. 114/2008 of the Council of Europe [12] asked EU Member States to identify and designate the European critical infrastructures, of the energy and transport sectors, and to assess 
the need to improve their protection, however, there have been identified and designated a small number of such critical infrastructures, some of them of European dimension were not included in this process.

The sectoral approach of the directive represented a challenge for the Member States, but, basically, the analysis focuses not only on the sectoral boundaries, but rather follows an approach of "a system" or "a service" (e.g.: hospitals, financial services).

A major benefit was, however, the fact that, at the community level, for the protection of the critical infrastructures, the general level of awareness and co-operation in the field mentioned in the European Union has increased, in particular as a result of the organization of various activities and forums held under the aegis of the Directive, in particular in the energy and transport sectors.

At the same time, the existence of a legal instrument encouraged the policies for the protection of the critical national infrastructures. In those circumstances, Directive No. 114/2008 of the Council of Europe is considered essential by most actors involved in this field. In addition, it is expected that the benefits of the directive, in particular those relating to increasing awareness, to continue to grow.

By this approach, an environment of trust and common goals can be sustained further on.

\subsection{Critical Infrastructure Warning Information Network-CIWIN}

CIWIN network is an initiative of the Directorate for Internal Affairs of the European Commission, an important pillar of the European Program for Critical Infrastructure Protection which aims at improving the protection of critical infrastructures in all the Member States of the European Union and in all sectors of activity.

The release on a European Program for Critical Infrastructure Protection in 2006 called on the creation of a warning information network related to critical infrastructures, a system based on information and communication for the exchange and analysis of information relating to critical infrastructure protection, studies and/or best practices among communities in the area. CIWIN was put in practice in October 2012, being operational since January, 2013. In the first few months of operation, there were positive contributions, including an increase in the use of statistics and of the section devoted to national objectives for CIWIN.

CIWIN network was developed as a secured system of the European Commission of communication and information relating to the exchange of information in the field of critical infrastructure protection, which gives the members of European Commission the opportunity to discuss and exchange information, studies and best practices in all economic sectors.

CIWIN platform was launched without the rapid alert component due to the fact that the Member States had considered that its safety measures are insufficient.

CIWIN is expected to continue to improve as an interactive tool for the EU developing approach in the field of reference.

It should be stressed that CIWIN will not revolutionize security in the European Union and that it should be considered as one of the many stages of implementation of the European Program for Critical Infrastructure Protection.

Therefore, CIWIN is an informatics tool intended to facilitate communication on issues related to the protection of critical infrastructure and provides functions (information bulletins, collaborative data storage, discussion boards, document and workflow management functions) which are current information on the internet.

3.3. External dimension of the The European Programme for Critical Infrastructure Protection (EPCIP)

The Council mandated the Commission to develop the external dimension of the European Program for Critical 
Infrastructure Protection in the framework of the conclusions of June, 2011 [13]. The document calls both the Commission and the Member States to strengthen cooperation with third countries in order to exchange best practices, but also to identify critical infrastructures in third countries which could potentially affect them and vice versa.

The Member States have agreed that the external dimension has a particular importance for the protection of critical infrastructure. Cooperation with the countries of the European Free Trade Association (EFTA) is considered a priority. To formalize this cooperation with European Economic Area (EEA), the Commission presented a proposal for a decision of the Council on the expansion and the applicability of Directive No. $114 / 2008$ for the EEA countries as well. [14], which means the establishment of a Joint Decision Committee of the EEA regarding the identification and designation of European critical infrastructures [15]. Both Norway and Iceland have recently confirmed the constitutional requirements related to the implementation of this Decision [16].

The proposed regulation establishes an Instrument for Stability (IfS) [17]-an instrument for external cooperation-to enable the provision of assistance in the protection of critical infrastructure of a third party, in the field of international transport (aviation and maritime), energy infrastructures and operations as well as communications networks and electronic information (cyber security).

In addition, in order to strengthen the strategic partnerships beyond Europe, the European Union-United States of America and the European Union-Canada, on an annual basis, meetings of experts were organized, the last being in May 2014. These meetings have mainly dealt with the need to consolidate cooperation through knowledge sharing, best practices and information on the protection of critical infrastructure, including the development of a comprehensive set of tools for the safety of infrastructures.

Its purpose will be to promote the exchange of best practices, methodologies, analysis, lessons learned, and other materials that may be useful, between the European Union, United States of America and Canada.

\section{Shaping a new approach of the European Program for Critical Infrastructure Protection}

This approach must be implemented stepby-step after the crystallization of the concept that should provide an opportunity to take into account the cross-sectoral factors within the process of consolidation of the activities relating to the protection of critical infrastructure.

The pilot program conducted with the four designated European critical infrastructure at the level of the European Commission, must ensure a comprehensive understanding of their measures on the protection of critical infrastructure established in each set of action directions concerning the prevention, preparedness and response, in order to optimize their protection and resilience.

\subsection{Prevention-intervention priority directions:}

- stage assessment in order to determine the progress made in the case of security measures and interdependencies with other sectors (IT \& C, water supply, etc.);

- establishing instruments for risk management;

- development of risk assessment methodologies with low-probability events with high consequences that can be applied in the upcoming "stress tests" for critical infrastructures;

- coordination mechanisms for prevention, preparedness and improving private sector involvement.

\subsection{Preparation-intervention priority} directions:

- the development of training strategies based on the various action plans, stress tests, raising awareness, training, 
joint action, exercises and exchange experience;

- implementation of reporting of incidents, which may be promoted as a method of increasing the level of knowledge concerning the performance of critical infrastructures during of a disruptive event (for example: the magnitude of the effects of domino, the overall impact, etc.);

- promoting and facilitating dialogue between the operators of critical infrastructures in order to improve the overall response capacity;

- assessing the possibility of interconnection network for preparedness.

4.3. The answer-intervention priority directions:

- strengthening the links among the critical infrastructures and early warning systems, taking into account the fact that the early warning mechanisms for natural disasters may highlight possible threats to critical infrastructures;

- assessment of the possibilities for the use of specialists to provide assistance concerning the long-term restoration of critical services, which can be mobilized at the request of the Member States.

In the context described, the new approach of the European Union can encourage and support the development of critical infrastructure protection, at all levels, from the local and national, to European and international ones, by transforming the Union into a macrostructure that is more secured and better prepared in the face of threats to its critical infrastructures and by improving its resilience in case of disruptive events.

\section{References}

[1] Directive No. the Council of Europe, 114 of 8 December 2008 on the identification and designation of European critical infrastructures and the assessment of the need to improve their protection. Official Journal of the European Union/75, article L375. 2 (a).

[2] The conclusions of the European Council of 10/11 December 2009 on the "Stockholm Program-an open and secure Europe serving and protecting the citizens (2012-2014)."

[3] COM (2010) 673 final. National Security Strategy of the European Union: 5 steps to a safer Europe. Goal 2: prevent terrorism and concentrating on radicalization and recruitment. Goal 5: increase resilience of Europe in crisis situations and disasters.

[4] $\operatorname{COM}(2006) 786$ final.

[5] Directive No. 114 of the Council of Europe, December 8, 2008 on the identification and designation of European critical infrastructures and the assessment of the need to improve their protection. Official Journal of the European Union L375/75.

[6] Interdependence: "a bidirectional relationship between two infrastructures through which the state of each infrastructure is influenced by or correlated to the state of the other," Steven M. Rinaldi, James P. Peerenboom, Terrence K. Kelly, Identifying, Understanding and Analyzing Critical Infrastructure Interdependencies. IEEE Control Systems Magazine, December 2001, p. 14

[7] Working document of the Commission on the Review of the European Program for Critical Infrastructure Protection, (EPCIP), SWD (2012) 190 final

[8] In the context of operationalizing and the functioning of the Single European Sky, EUROCONTROL Agency has been appointed as the Network Manager for The European Union of Air Traffic Management (ATM). This has required the establishment of some cooperation links for consultation and decision making between all actors involved in air traffic operations (for example: national suppliers of air transport services, airspace users, airports, the competent national authorities and the armed forces, both at the level of authority on the matter, and as provider of services). 
An important activity of the operational network Manager is the coordination of the Management of air traffic flow with organizations throughout Europe who are in charge of the air traffic control.

Within this framework, one of the tasks of the Network Manager is to provide support for crisis management network: a European Coordination Cell Crisis in Aviation (ECCCA), composed of the permanent representatives of all the shareholders of the MTA and the various institutions of the European Union, as well as focal points of the respective Member States ' structures, was previously established to mitigate the effects of potential crisis network. Its activity consists in regular meetings to simulate possible scenarios with serious consequences for aviation, and which may be declared as crisis events to network, as well as for the organization of ad hoc events with focal points in the Member States. The Network Manager, alongside with ECCCA members, can activate and disable ECCCA, by coordinating the response to the crisis management network, monitoring the implementation of the action plans and proposing procedures, where there is a plan of action.

EUROCONTROL functioning as a Network Manager and of CECCA, may be the subject of a case study on a large scale, developed by DGHOME in collaboration with other interested departments, aimed at identifying good practices in the implementation of the measures regarding the prevention, security and response, leading to the formulation of risk mitigation strategies which also contribute to a more suitable protection of critical infrastructures and sectors.

Its complex infrastructure, responsive to a multitude of scenarios of threats, including cyber attacks, in which the disruption of its services can have a significant impact at the level of European economy, as well as the interrelationship of its subsystems that involve cascading effects/domino-type, can also be an interesting topic for a case study.

[9] Space technology-based systems introduce a wide spectrum of applications that play a fundamental role in our daily work, and are critical for key areas of the economy and facilitate our security. With the increasing reliance on services provided by using spatial technology, the capability of the space infrastructure has become essential to our society. Any interruption in the operation, even partial, of the spatial infrastructure can have significant consequences for the proper functioning of economic activities and the safety and security of citizens, and it would disrupt the provision of urgent services. This applies in particular for Galileo - the European Global Navigation Satellite System (EGNSS) which is the first space infrastructure owned by the European Union. A major failure, whether accidental or intentional, also EGNSS infrastructure would have an impact on users but will also affect many other critical infrastructures in which EGNSS services are deeply integrated: transport, telecommunications, trade and banking activities are based on EGNSS signals for synchronization, navigations and secure transactions.

Galileo, as other spatial infrastructures, is subject to specific threats to satellites and signals. EGNSS transmissions may be susceptible to a number of threats through the prism of the connections of radiofrequency interference, such as unauthorized access and misuse, jamming, spoofing and cyber attack. The Galileo system has been subject to specific security processes designed to reduce the induced risks. Additionally, one of Galileo's services, The Public Regulated Service (PRS), was specifically enacted to assist the Member States and government-authorized users, for sensitive applications which require an effective access control provided on an unlimited and uninterrupted global scale.

In addition, the steady growth of the number of scrap space has become a serious threat to the resilience of space activities, including operation of constellation of Galileo satellites, of the space segment Copernicus, or national public and commercial satellites. To reduce 
the risk of collision it is necessary to identify and monitor satellites and space debris, cataloging positions and monitoring their trajectory, when the risk of collision was identified, to alert operators of satellites with a view to repositioning them. This activity is known as surveillance and monitoring of space (SMS) and is currently based in large part on the ground sensors, such as telescopes and cameras. Currently, there is no SMS capability at EU level: the satellite operators are dependent on data issued by US for anticollision alerts.

The Commission issued a proposal for a European support program for the surveillance and monitoring of space. The objective of the program is the provision of assistance to Member States for their cooperation and interconnection capacity in order to provide SMS alerting anti-collision services at European level.

[10] As demonstrated in previous years, as a result of current outages on extended areas, a single incident affecting a significant element of the network, can affect the supply to the entire continent. Threats (produced by humans) have a similar cross-border operation, while the attackers or coordinated actions may concern the networks at regional, European or international level, in the case of cyber attacks.

An interruption of the electricity supply of major dimensions occurred within the transmission network in Northern Germany, on November 4, 2006 and was felt in most parts of the continent, beyond the borders of Germany to France, Belgium, Austria, Slovenia and Spain. Even if the actions taken by energy transmission system operators (ETSO) have prevented power outage, this case is considered to be one of the most severe and major disruptions of this kind in Europe. The effects were major from the point of view of disruption in the supply of electricity at industrial and domestic level (more than 15 million households) as well, and the electricity-dependent services, such as transport, have been affected (for example: hundreds of railway transports were postponed or cancelled).

Thus, it requires a coordinated mechanism of protection, involving all the operators and their sectoral branches. Risks associated to the threats described above can be adequately addressed only at the system level, bearing in mind that the integrity and the functionality of the entire system are affected. This sector (especially ENTSO-E) has already invested in CIP measures and has expressed support for a European Union approach that will integrate the requirements imposed by the rules of the internal market. The code of networks provides a legislative support for the incorporation of common methodologies of protection for European operators of electricity transport networks. The Commission can support this process, during the following years, in terms of providing CIP tools and methods.

Additionally, the development towards Intelligent Networks requires enhanced synergies between the sectors of information technology and communications (ICT) and energy. More than ever, the industry and investors are worried about the prospect of cyber attacks. In this respect, the Commission has initiated actions through the Intervention Team for Intelligent Networks, in which experts from the ICT and energy sector put up a framework for evaluation of cyber security. This framework includes the evaluation of the current methodologies for a stable network, disseminating the analyses of threats and vulnerabilities related to Intelligent Networks and smart metering systems, as well as identify the best techniques for smart metering systems.

[11] Physical threats (from terrorism, the boycotts and strikes), destructive natural events (earthquakes, floods, low temperatures, storms) and commercial disputes to which this network is subjected, make it vulnerable and threaten Europe's access to natural gas.

A relevant example of the effects of a disturbance on the transport network natural gas pipeline is that of the Fellowship pipeline in 2009. This pipeline, which carries daily 
nearly 300 million cubic meters of Russian natural gas through Ukraine to Europe, began to reduce the flow rate at the beginning of January, the transport being due to be stopped completely. The disturbance had a significant impact on many Member States, especially on those which entirely depend on this supply route, leaving households without heat and causing the abandonment of production in certain industries. Gas supply was fully restored on 21 January 2009. This disturbance was the most important of its kind in Europe's recent history: for an unprecedented period of 2 weeks, Europe was deprived of $30 \%$ of natural gas imports, which equals $20 \%$ of the stock of natural gas.

The need for coordination, at European level, thus becomes clear and is recognized by the Natural Gas Infrastructure of Europe (NGIE), representing the operators in this sector. NGIE has expressed support of EPCIP program and proposed the development of a common methodology for the analysis of risks/threats in Europe for natural gas infrastructures, having an approach of all the hazards. This would be consistent with the coordination implemented in natural gas by the Council regulation 994/2010, namely preparing for a national risk analysis, establishment of preventive measures and the elaboration of emergency plans based on a profound risk analysis.

[12] Directive No. 114/2008 of the Council of Europe of December 8, 2008 on the identification and designation of European critical infrastructures and the assessment of the need to improve their protection. Official Journal of the European Union L345/75.

[13] European Council conclusions of June 9/10, 2011 on the development of the external dimension PEPIC.

[14] Proposal for athe EFTA Council decision on the position to be adopted by the European Union within the framework of the EEA Joint Committee, on an amendment to Protocol 31 of the EEA Agreement, on cooperation in specific fields, other than the four freedoms.

[15] The Joint Committee of the EEA Decision 101/2012 (identification and designation of European critical infrastructure).

[16] Notifications from Norway (7/12/2012) and Iceland (4/3/2013) for the specific constitutional requirements of decision No. 101/2012-improvement of Protocol 31 of the EEA Agreement-the Council of Europe Directive No. 114/2008.

[17] COM (2011) 845 final. 